\title{
Platelet count to spleen diameter ratio for the diagnosis of esophageal varices: Is it feasible?
}

\author{
Waqas Wahid Baig MBBS MD FAGE, MV Nagaraja MD, Muralidhar Varma MD, Ravindra Prabhu MD DM DNB
}

\begin{abstract}
WW Baig, MV Nagaraja, M Varma, R Prabhu. Platelet count to spleen diameter ratio for the diagnosis of esophageal varices: Is it feasible? Can J Gastroenterol 2008;22(10):825-828.
\end{abstract}

AIM: To study the value of platelet count to spleen diameter ratio as a noninvasive parameter for diagnosing esophageal varices $\left(E V_{s}\right)$ in liver cirrhosis.

METHODS: The laboratory and ultrasonographic variables were prospectively evaluated in 150 patients with liver cirrhosis. Only stable patients were included in the study. Patients with active gastrointestinal bleeding at the time of admission were excluded. All patients underwent screening upper gastrointestinal endoscopy.

RESULTS: The platelet count, spleen diameter and platelet count to spleen diameter ratio in patients with EVs were significantly different from patients without EVs. The platelet count to spleen diameter ratio had the highest accuracy among the three parameters. By applying receiver operating characteristic curves, a platelet count to spleen diameter ratio cut-off value of 1014 was obtained, which gave positive and negative predictive values of $95.4 \%$ and $95.1 \%$, respectively. The accuracy of this cut-off value as evaluated by applying receiver operating characteristic curves was 0.942 (95\% CI 0.890 to 0.995).

CONCLUSION: Among the noninvasive parameters studied, platelet count to spleen diameter ratio had the highest accuracy for diagnosing EVs. However, the evidence for the noninvasive diagnosis is not yet sufficient to replace endoscopy as a diagnostic screening tool for EVs in all cirrhotic patients. The platelet count to spleen diameter ratio may be a useful tool for diagnosing EVs in liver cirrhosis noninvasively when endoscopy facilities are not available.

Key Words: Endoscopy; Esophageal varices; Liver cirrhosis; Platelet count; Platelet count to spleen diameter ratio; Portal hypertension; Spleen diameter

\section{Le ratio entre la numération plaquettaire et le diamètre de la rate pour diagnostiquer les varices œsophagiennes : Est-ce faisable?}

OBJECTIF : Étudier la valeur du ratio entre la numération plaquettaire et le diamètre de la rate comme paramètre non effractif pour diagnostiquer les varices œsophagiennes (VO) en cas de cirrhose du foie.

MÉTHODOLOGIE : Les auteurs ont procédé à l'évaluation prospective des variables de laboratoire et d'échographie de 150 patients atteints de cirrhose du foie. Seuls les patients stables ont participé à l'étude. Les patients atteints de saignement gastro-intestinal actif à l'hospitalisation ont été exclus. Tous les patients avaient subi un dépistage par endoscopie œsogastroduodénale.

RÉSULTATS : La numération plaquettaire, le diamètre de la rate et le ratio entre la numération plaquettaire et le diamètre de la rate des patients ayant des $\mathrm{VO}$ étaient considérablement différents de ceux des patients sans VO. Le ratio entre la numération plaquettaire et le diamètre de la rate était le plus précis des trois paramètres. Au moyen des courbes de fonction d'efficacité du récepteur, les auteurs ont obtenu une valeur seuil du ratio entre la numération plaquettaire et le diamètre de la rate de 1014 , qui avait des valeurs prédictives positives et négatives de $95,4 \%$ et 95,1\%, respectivement. La précision de cette valeur seuil, évaluée par l'application des courbes de fonction d'efficacité du récepteur, correspondait à 0,942 (95\% IC 0,89 à 0,995).

CONCLUSION : Parmi les paramètres non effractifs à l'étude, le ratio entre la numération plaquettaire et le diamètre de la rate était le plus précis pour diagnostiquer les VO. Cependant, le diagnostic non effractif n'est pas encore assez probant pour remplacer l'endoscopie comme outil de dépistage diagnostique des VO chez tous les patients cirrhotiques. En l'absence d'installations endoscopiques, le ratio entre la numération plaquettaire et le diamètre de la rate peut être un outil utile pour diagnostiquer les $\mathrm{VO}$ de manière non effractive en cas de cirrhose du foie.
$\mathrm{N}^{2}$ oninvasive diagnosis of esophageal varices (EVs) in cirrhotic patients is useful because it allows us to select the subgroup of patients that are most likely to require endoscopy; at the same time, it minimizes the cost and the potential complications related to the procedure. The incidence of cirrhosis is increasing and so is the survival of cirrhosis patients due to the improvements and advances in health care. The medical and social burden of the disease will likely increase in the future. Several attempts have been made to identify the parameters that can noninvasively predict the presence of EVs. Most studies have shown that platelet count and spleen diameter are directly or indirectly linked to the presence of EVs.

The platelet count to spleen diameter ratio, proposed by Giannini et al (1), appears to be the best noninvasive predictor of EVs that has been developed so far.

The present study attempts to prospectively evaluate the validity of platelet count to spleen diameter ratio by comparing it with other noninvasive parameters that can be used to screen for the presence of EVs in patients with liver cirrhosis.

Department of Medicine, Kasturba Medical College, Manipal, Karnataka, India

Correspondence: Dr Waqas Wahid Baig, Department of Medicine, Kasturba Medical College, Manipal, Karnataka 576104, India.

Telephone 91-820-292-2442, fax 91-820-257-1934 or 91-820-257-0062,e-mail drwaqaswahid@gmail.com or waqaswahid@yahoo.co.in

Received for publication April 23, 2008. Accepted July 11, 2008 
TABLE 1

Main characteristics of the two groups of patients

\begin{tabular}{|c|c|c|c|}
\hline Variable & Esophageal varices present $(n=106)$ & Esophageal varices absent $(n=44)$ & $\mathbf{P}$ \\
\hline Age, years, median (range) & $50(21-80)$ & $52(20-79)$ & Not significant \\
\hline Sex, male:female & 88:18 & $38: 6$ & Not significant \\
\hline Platelet count, $\times 10^{9} / \mathrm{L}$, median (range) & $90.5(26-186)$ & $156.5(59-452)$ & $<0.001$ \\
\hline Spleen diameter, mm, median (range) & $140(80-200)$ & $100(70-170)$ & $<0.001$ \\
\hline Platelet count to spleen diameter ratio, median (range) & $702(140-1065)$ & $1300(388-5650)$ & $<0.001$ \\
\hline
\end{tabular}

Statistical analysis was performed using the Mann-Whitney $U$ and $\chi^{2}$ tests. All three parameters showed a statistically significant difference between the two groups of patients

\section{METHODS}

One hundred fifty patients with liver cirrhosis who were admitted to Kasturba Medical College (Manipal, Karnataka, India) between January 2004 and November 2007 were prospectively studied. Kasturba Medical College is a tertiary care centre located in the western coastal area of the Karnataka state. All stable patients with liver cirrhosis (irrespective of etiology) were included in the study. The patients included were either referred to the hospital for upper gastrointestinal endoscopy or were diagnosed with cirrhosis for the first time at Kasturba Medical College. The referred cases included in the study were of patients who were being managed in centres with no endoscopy facilities. These patients were diagnosed with cirrhosis and were referred for either screening endoscopy or upper gastrointestinal bleeding during the course of their disease. Diagnosis of cirrhosis was based on physical findings, laboratory investigations and radiological findings. Patients who were on primary prophylaxis for EVs, who presented with active gastrointestinal bleeding, and who previously underwent sclerotherapy, band ligation or surgery for EVs were not included in the study.

All patients underwent a detailed clinical examination and a biochemical workup, including total bilirubin, aspartate aminotransferase, alanine aminotransferase, serum albumin and prothrombin activity. Child-Pugh score was calculated for all patients. An upper gastrointestinal endoscopy was performed in all patients, and an ultrasound of the abdomen was done to measure the maximum spleen bipolar diameter and to look for signs of portal hypertension (splenomegaly, ascites, and portal vein diameter greater than $12 \mathrm{~mm}$ in women and greater than $14 \mathrm{~mm}$ in men). The upper gastrointestinal endoscopy was performed by a single investigator who was blinded to the laboratory results and the ultrasound parameters when the sizes of the EVs were scored.

All endoscopies were performed in a single endoscopy unit using a video endoscope (EC-200LR; Fujinon Inc, USA), and varices were classified into three grades: grade 1 , the varices could be depressed by the endoscope; grade 2 , the varices could not be depressed by the endoscope; and grade 3, the varices were confluent around the esophagus (2).

The platelet count to spleen diameter ratio was calculated for all patients in the study. The platelet count, spleen diameter and platelet count to spleen diameter ratio were compared between the two groups of patients with and without EVs.

\section{Statistical analysis}

SPSS version 11.5 (SPSS Inc, USA) was used for the statistical analysis using the Mann-Whitney $\mathrm{U}$ test for continuous variables and the $\chi^{2}$ test for qualitative variables. P-values were significant at the $5 \%$ level. The receiver operating characteristic
(ROC) curve was applied to determine the cut-off values with best sensitivities and specificities for all three parameters. The validity of the model was measured by concordance statistics (equivalent to the area under the ROC curve). A model with a c-value above 0.7 is considered fair, while a c-value between 0.8 and 0.9 is good and a c-value greater than 0.9 indicates excellent diagnostic accuracy.

\section{RESULTS}

One hundred twenty-six men and 24 women were included in the study. The mean age was 51 years (range 20 to 80 years). The etiologies of cirrhosis were alcohol abuse $(n=73)$, hepatitis $B(n=39)$, hepatitis $C(n=14)$, cryptogenic $(n=13)$, postnecrotic $(n=5)$, autoimmune $(n=4)$ and Wilson's disease $(\mathrm{n}=2)$.

Among the 150 cirrhosis patients studied, 97 were ChildPugh class A (64.7\%), 32 were class B (21.3\%) and 21 were class C (14\%). One hundred six of 150 patients had EVs. Among the patients with EVs, 36 patients had grade 1 varices, 54 had grade 2 varices and 16 had grade 3 varices. All three parameters (ie, platelet count, spleen diameter and platelet count to spleen diameter ratio) were significantly different between the two groups of patients with and without EVs (Table 1).

The ROC curve was applied to determine the cut-off values with the best sensitivities and specificities for all three variables. A cut-off value of 1014 was obtained for platelet count to spleen diameter ratio, which gave a sensitivity of $98.1 \%$ and a specificity of $88.6 \%$. The area under the ROC curve was 0.942 (95\% CI 0.890 to 0.995 ), indicating excellent diagnostic accuracy (Table 2).

All three parameters were significantly different between the two groups. However, the platelet count to spleen diameter ratio was the only parameter with the highest accuracy for identifying the presence of EVs in cirrhosis patients; it was consistently associated with the presence or absence of EVs (the area under the ROC curve was 0.942 [95\% CI 0.890 to 0.995]) (Table 2). The positive and negative predictive values for the platelet count to spleen diameter ratio were $95.4 \%$ and $95.1 \%$, respectively.

Both platelet count and spleen diameter cut-off values that yielded the best sensitivity and specificity for identifying EVs by applying ROC curves had sensitivities and specificities that were lower than those of the platelet count to spleen diameter ratio.

The sensitivity and specificity were also calculated for the platelet count to spleen diameter ratio cut-off of 909 (obtained in the original study by Giannini et al); the values obtained in the present study were $80 \%$ and $89 \%$, respectively. These values were lower than those of the study by Giannini et al, but were still acceptably high. 


\section{TABLE 2}

Comparison of accuracy of the three parameters in predicting the presence of esophageal varices (EVs)

\begin{tabular}{lccccccccc}
\hline Variable & EVs present & EVs absent & $\mathbf{P}$ & Cut-off & Sensitivity, \% & Specificity, \% & PPV, \% & NPV, \% & c index (95\% CI)* \\
\hline PLT, $\mathrm{n} / \mathrm{mm}^{3}$ & 90,500 & 156,500 & $<0.001$ & $<122,500$ & 80.2 & 75.0 & 88.54 & 61.1 & $0.844(0.772-0.915)$ \\
SD, $\mathrm{mm}$ & 140 & 100 & $<0.001$ & $>112.5$ & 74.5 & 68.2 & 84.90 & 52.6 & $0.764(0.678-0.851)$ \\
PLT:SD & 702 & 1300 & $<0.001$ & $>1014$ & 98.1 & 88.6 & 95.40 & 95.1 & $0.942(0.890-0.995)$ \\
\hline
\end{tabular}

Among the three parameters, the platelet count (PLT) to spleen diameter (SD) ratio demonstrated the highest accuracy. ${ }^{*}$ The $c$ index is equivalent to the area under the receiver operating characteristic curve. NPV Negative predictive value; PPV Positive predictive value

\section{DISCUSSION}

At the time of a liver cirrhosis diagnosis, EVs are present in approximately $40 \%$ of patients with early disease and in approximately $60 \%$ of those with decompensated disease $(3,4)$.

The yearly incidence of gastrointestinal bleeding is $1 \%$ to $2 \%$ in patients without EVs, $5 \%$ in those with small EVs and $15 \%$ to $20 \%$ in patients with large EVs (4). Endoscopy is recommended every two to three years in patients without varices, and every one to two years in patients with small varices $(1,5,6)$. In an attempt to reduce the increasing burden on endoscopy units, several studies have been performed to identify the noninvasive parameters that can predict the presence of EV in liver cirrhosis (1).

The management of patients with liver cirrhosis has advanced over the past few decades, resulting in improved survival (7-11). However, bleeding from ruptured EVs is still the leading cause of death in patients with cirrhosis. In recent studies, mortality figures were between $11 \%$ and $20 \%$ within six weeks of the bleeding episode (8-11). Therefore, prevention of variceal bleeding should be an important goal. The first crucial step in the prevention of variceal bleeding is to identify the patients at risk for bleeding from EVs, so that they can be selected for prophylactic treatment. Varices eventually develop in all patients with liver cirrhosis and they tend to increase in size with time and bleeding. We also know that the prevalence of varices is higher in decompensated than in compensated cirrhosis, and that large varices have a higher propensity to bleed than small varices (12).

At a given point in time, a proportion of cirrhosis patients especially the ones with compensated disease - will not have varices. The reported prevalence of $E V s$ is varied, ranging from $24 \%$ to $80 \%$ (12). Diagnosing EVs by noninvasive means would restrict the performance of endoscopy in patients with a high probability of having varices.

Several studies (13-19) have shown that platelet count and spleen diameter correlate well with the presence of EVs. However, in patients with chronic liver disease, the presence of a decreased platelet count may depend on several factors other than portal hypertension, such as shortened mean platelet lifetime, decreased thrombopoietin production or myelotoxic effects of alcohol or hepatitis viruses (20). On the other hand, the presence of splenomegaly in cirrhotic patients is likely the result of vascular disturbances that are mainly related to portal hypertension. With this in mind, Giannini et al attempted to devise a new parameter that might be more consistent with the noninvasive diagnosis of $\mathrm{EV} \mathrm{s}$ in cirrhotic patients.

The parameter connects thrombocytopenia to splenomegaly to introduce a variable that takes into consideration the decreased platelet count most likely attributed to hypersplenism caused by portal hypertension (20). Several studies (21-25) have been performed in an attempt to validate this new parameter as a new noninvasive screening tool for $\mathrm{EV}$.
In the present study, we attempted to validate the platelet count to spleen diameter ratio as a screening test for $\mathrm{EVs}$ in patients from India.

Performing endoscopy on all cirrhosis cases would cost $\$ 4,272$, whereas performing endoscopy only in patients with the platelet count to spleen diameter ratio cut-off of more than 1014 would cost $\$ 3,133$. Comparing the two strategies, the mean per-patient, per-month cost difference between the two approaches would be $\$ 0.165$. The difference is only minimal; however, by applying the ratio cut-off of 1014 to the patients evaluated in the present study, we could have avoided 40 unnecessary endoscopies. Two patients (with small varices) would have been missed by application of the present diagnostic model. Ultrasound of the abdomen, which is performed routinely in cirrhosis patients, can be used to measure spleen bipolar diameter. The platelet count to spleen diameter ratio can be calculated and used to detect the presence or absence of EVs. This noninvasive screening model may be useful in decreasing unnecessary endoscopies or medication (prophylactic medication for EVs).

The limitations of our study include the following: the liver biopsy was not performed; the diagnosis of cirrhosis was based on clinical, noninvasive laboratory results; and the ultrasound parameters and the subgroup of patients with variceal bleeding were not included.

\section{CONCLUSION}

Among the noninvasive parameters studied, the platelet count to spleen diameter ratio had the highest accuracy for diagnosing EVs. However, most current guidelines (26-28) recommend that all cirrhotic patients be screened by upper gastrointestinal endoscopy for the presence of EVs at the time of diagnosis. This argues against the accuracy of noninvasive predictors of EVs. As discussed previously, the screening upper gastrointestinal endoscopy is recommended every two to three years in patients without varices, and repeat endoscopy is recommended every one to two years in patients with small varices. However, the platelet count to spleen diameter ratio may prove to be a useful tool for diagnosing EVs in liver cirrhosis noninvasively when resources are limited and endoscopy facilities are not available, to select the subgroup of cirrhosis patients likely to have EVs who can be referred to centres with such facilities.

More studies may be required in a larger population of cirrhosis patients for validation of the ratio proposed by Giannini et al and to determine a cut-off value that can be safely recommended for the noninvasive diagnosis of $\mathrm{EV}$.

\section{REFERENCES}

1. Giannini E, Botta F, Borro P, et al. Platelet count/spleen diameter ratio: Proposal and validation of a non-invasive parameter to predict the presence of oesophageal varices in patients with liver cirrhosis. Gut 2003;52:1200-5.

2. Prediction of the first variceal hemorrhage in patients with cirrhosis of the liver and esophageal varices. A prospective 
multicenter study. The North Italian Endoscopic Club for the Study and Treatment of Esophageal Varices. N Engl J Med 1988;319:983-9.

3. Schepis F, Camma C, Niceforo D, et al. Which patients with cirrhosis should undergo endoscopic screening for esophageal varices detection? Hepatology 2001;33:333-8.

4. D’Amico G, Luca A. Natural history. Clinical-hemodynamic correlations. Prediction of the risk of bleeding. Bailliere's Clin Gastroenterol 1997;11:243-56.

5. D'Amico G, Pagliaro L. The clinical course of portal hypertension in liver cirrhosis. In: Rossi P, ed. Diagnostic Imaging and Imaging Guided Therapy. Berlin: Springer-Verlag, 2000:15-24.

6. D’Amico G, Pagliaro L, Bosch J. Pharmacological treatment of portal hypertension: An evidence based approach. Semin Liver Dis 1999;19:475-505

7. Pagliaro L, D'Amico G, Pasta L, et al. Efficacy and efficiency of treatments in portal hypertension. In: de Franchis R, ed. Portal Hypertension II, Proceedings of the Second Baveno International Consensus Workshop on Definitions, Methodology and Therapeutic Strategies. Oxford: Blackwell Science, 1996:159-79.

8. D’Amico G, de Franchis R; Cooperative Study Group. Upper digestive bleeding in cirrhosis. Post-therapeutic outcome and prognostic indicators. Hepatology 2003;38:599-612.

9. Chalasani N, Kahi C, Francois F, et al. Improved patient survival after acute variceal bleeding: A multicenter, cohort study. Am J Gastroenterol 2003;98:653-9.

10. Carbonell N, Pauwels A, Serfaty L, et al. Improved survival after variceal bleeding in patients with cirrhosis over the past two decades. Hepatology 2004;40:652-9.

11. Di Fiore F, Lecleire S, Merle V, et al. Changes in characteristics and outcome of acute upper gastrointestinal haemorrhage: A comparison of epidemiology and practices between 1996 and 2000 in a multicentre French study. Eur J Gastroenterol Hepatol 2005;17:641-7.

12. de Franchis R. Noninvasive diagnosis of esophageal varices: Is it feasible? Am J Gastroenterol 2006;101:2520-2.

13. Thomopoulos KC, Labropoulou-Karatza C, Mimidis KP, et al. Non-invasive predictors of the presence of large oesophageal varices in patients with cirrhosis. Dig Liver Dis 2003;35:473-8.

14. Madhotra R, Mulcahy HEI, Willner I, et al. Prediction of esophageal varices in patients with cirrhosis. J Clin Gastroenterol 2002;34:4-5.
15. Chalasani N, Imperiale TF, Ismail A, et al. Predictors of large esophageal varices in patients with cirrhosis. Am J Gastroenterol 1999;94:3285-91.

16. Zaman A, Hapke R, Flora K, et al. Factors predicting the presence of esophageal or gastric varices in patients with advanced liver disease. Am J Gastroenterol 1999;94:3292-6.

17. Freeman JG, Darlow S, Cole AT. Platelet count as a predictor for the presence of oesophageal varices in alcoholic cirrhotic patients. Gastroenterology 1999;116:A1211. (Abst)

18. Barcia HX, Robalino GA, Molina EG, et al. Clinical predictors of large varices in cirrhotic patients. Gastrointest Endosc 1998;47:A78. (Abst)

19. Alacorn F, Burke CA, Larive B. Esophageal varices in patients with cirrhosis: Is screening endoscopy necessary for everyone? Am J Gastroenterol 1998;93:1673. (Abst)

20. Peck-Radosavljevic M. Thrombocytopenia in liver disease. Can J Gastroenterol 2000;14(Suppl D):60D-6D.

21. Alempijevic T, Bulat V, Djuranovic S, et al. Right liver lobe/albumin ratio: Contribution to non-invasive assessment of portal hypertension. World J Gastroenterol 2007;13:5331-5.

22. Giannini EG, Botta F, Borro P, et al. Application of the platelet count/spleen diameter ratio to rule out the presence of oesophageal varices in patients with cirrhosis: A validation study based on follow-up. Dig Liver Dis 2005;37:779-85.

23. Zimbwa TA, Blanshard C, Subramaniam A. Platelet count/spleen diameter ratio as a predictor of oesophageal varices in alcoholic cirrhosis. Gut 2004;53:1055

24. Korula J. Platelet count/spleen diameter ratio predicted the presence of esophageal varices in liver cirrhosis. ACP J Club 2004;140:53.

25. Giannini EG, Zaman A, Kreil A, et al. Platelet count/spleen diameter ratio for the noninvasive diagnosis of esophageal varices: Results of a multicenter, prospective, validation study. Am J Gastroenterol 2006;101:2520-2.

26. Kovalak M, Lake J, Mattek N, Eisen G, Lieberman D, Zaman A. Endoscopic screening for varices in cirrhotic patients: Data from a national endoscopic database. Gastrointest Endosc 2007;65:82-8.

27. Dib N, Konate A, Oberti F, Calès P. Non-invasive diagnosis of portal hypertension in cirrhosis. Application to the primary prevention of varices. Gastroenterol Clin Biol 2005;29:975-87.

28. Qamar AA, Grace ND, Groszmann RJ, et al; Portal Hypertension Collaborative Group. Platelet count is not a predictor of the presence or development of gastroesophageal varices in cirrhosis. Hepatology 2008;47:153-9. 


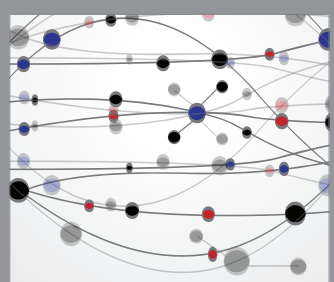

The Scientific World Journal
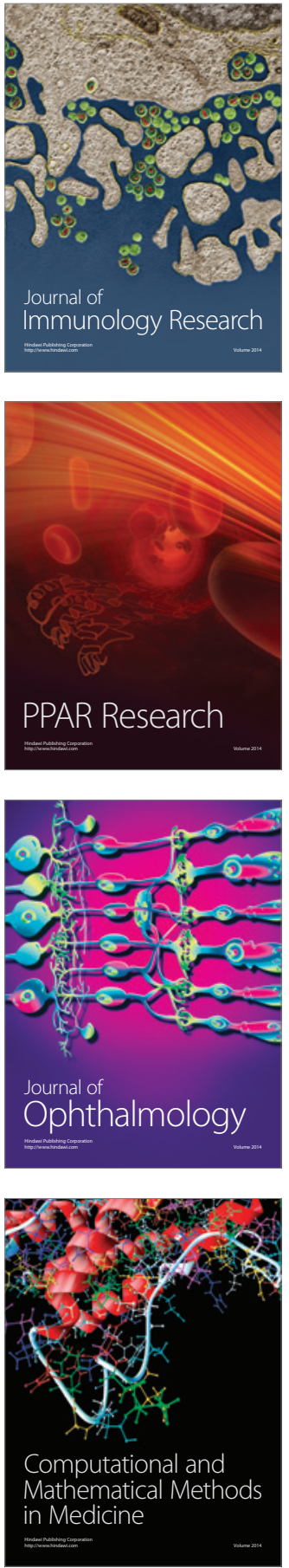

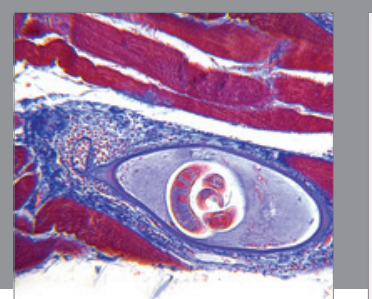

Gastroenterology Research and Practice

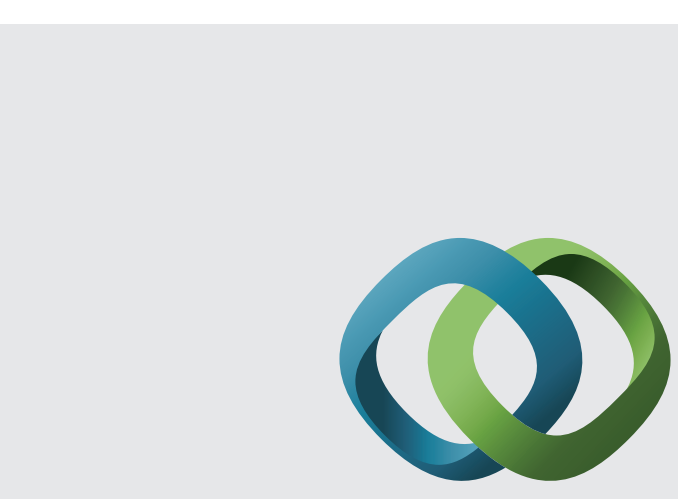

\section{Hindawi}

Submit your manuscripts at

http://www.hindawi.com
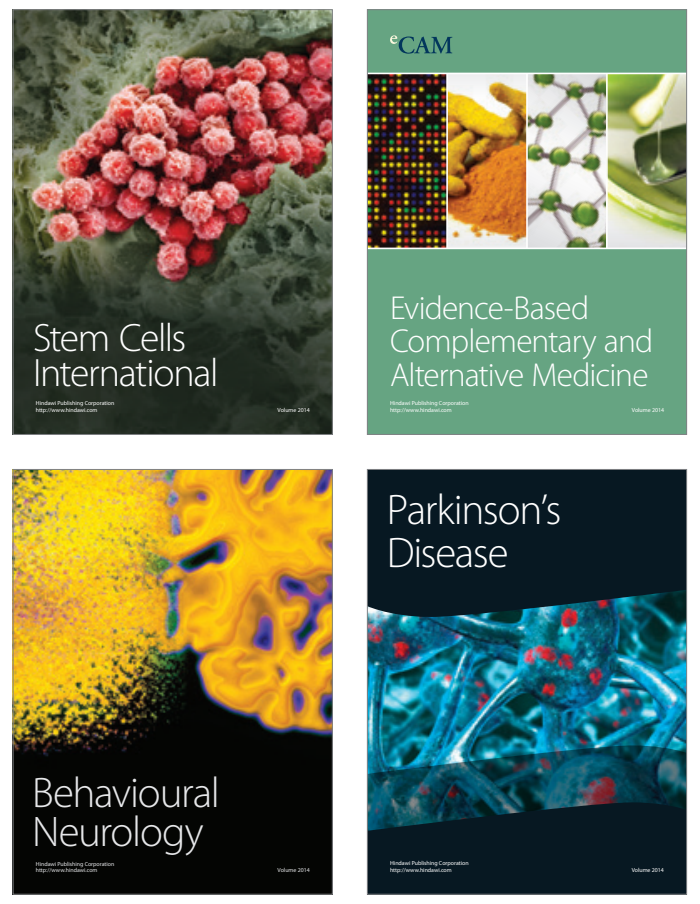
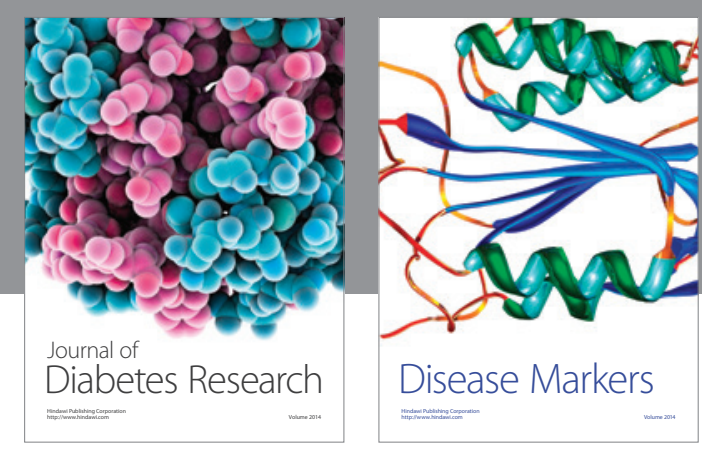

Disease Markers
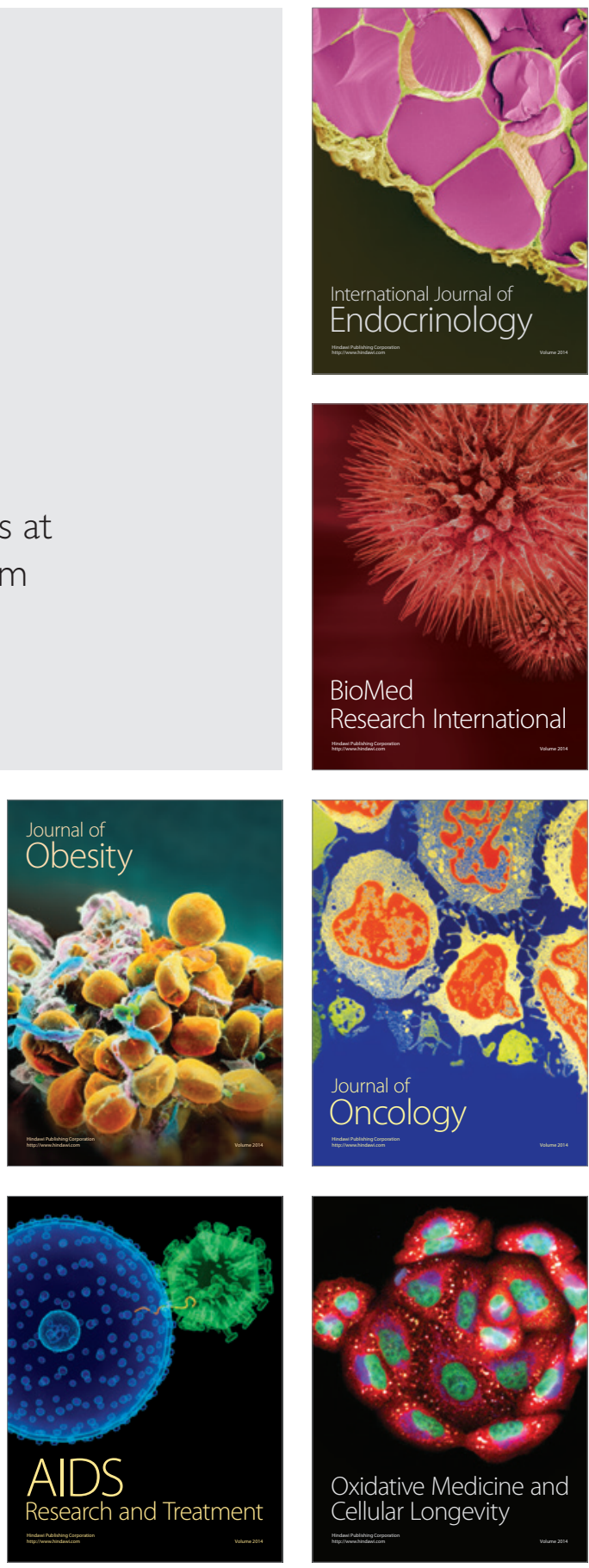